important that once factors have been developed, confirmatory data should be presented to validate the findings.

LIDDLE, P. F. (1987) The symptoms of chronic schizophrenia: a reexamination of the positive-negative dichotomy. British Journal of Psychiatry, 151, 145-151.

\& BARNES, T. R. E. (1990) Syndromes of chronic schizophrenia. British Journal of Psychiatry, 157, 558-561.

Mortimer, A. M., Lund, C. E. \& MCKenNA, P. J. (1990) The positive-negative dichotomy in schizophrenia. British Journal of Psychiatry, 157, 41-49.

Peralta, V., De Leon, J. \& Cuesta, M. J. (1992) Are there more than two syndromes in schizophrenia? A critique of the positivenegative dichotomy. British Journal of Psychiatry, 161, 335-343.

SONI, S. D., MAllik, A., ReED, P., et al (1992) Differences between chronic hospitalised schizophrenics and those living in the community: implications for clinical practice and research. Hospital and Community Psychiatry (in press)

SOM D. SONI

Sally Hollis

PAUL F. ReED

SHABIR MUSA

Hope Hospital

Salford

M6 $8 H D$

SIR: Peralta et al (Journal, September 1992, 161, 335-343) contribute to the developing consensus that factor analysis of schizophrenic symptoms yields at least three factors, consistent with the threesyndrome model (Liddle, 1987), but they conclude that a valid classification of symptoms has yet to be achieved. The evidence from a decade of scrutiny of the relationships between schizophrenic symptoms stimulated by Crow's concepts of type 1 and type 2 schizophrenia suggests that it is irrelevant to seek a classification such that each symptom belongs to a unique syndrome. The syndromes of schizophrenia are not discrete types of illness, but rather, groups of symptoms that coexist with each other more frequently than with those from other groups. Thus the symptoms of schizophrenia form a constellation of syndromes, all of which are related, but some of the relationships are closer than others.

The relationships revealed by factor analysis depend on the range of phenomena embraced by individual items and by the range of items entered into the analysis. Different choice of symptom rating scales will lead to emphasis on different aspects of the relationships between symptoms. This was demonstrated in my original study (Liddle, 1987), in which I analysed two different sets of symptom scores. The analysis of PSE scores produced a four-factor solution in which two factors reflected reality distortion. Delusions and hallucinations segregated into paranoic and Schneiderian groups. Some analyses will emphasise relationships that cross the boundaries within the three-syndrome model. For example, the relationship between formal thought disorder and some types of delusions is quite strong, so if the symptom rating scale combines all delusions into a single score (as in the Krawiecka scale), there will be overlap between items loading on the factors representing the disorganisation and reality distortion syndromes, as was found by Liddle \& Barnes (1990).

Insofar as relationships between symptoms reflect relationships in the pathophysiological processes that generate the symptoms (rather than mere artefacts of measurement procedure), examination of the pattern of relationships between symptoms might yield useful insights into the underlying pathophysiology. The three-syndrome model led me to propose three specific cerebral sites for the abnormalities associated with the three syndromes. These specific predictions were confirmed in a study of regional cerebral blood flow (Liddle et al, 1992). Furthermore, in accord with expectation, the specified sites were part of three overlapping patterns of disturbed function in multimodal association cortex. An analysis of the data using canonical correlation demonstrated the areas of overlap between the different syndromes (Friston et al, 1992). In particular, the left medial temporal lobe was implicated in all three syndromes. Thus, despite the clinical heterogeneity of schizophrenia, contemporary evidence reinforces Kraepelin's amalgamation of catatonia, hebephrenia and dementia paranoides to form a single disease.

LiddLe, P. F. (1987) The symptoms of schizophrenia: a reexamination of the positive-negative dichotomy. British Journal of Psychiatry, 151, 145-151.

\& BARNES, T. R. E. (1990) Syndromes of chronic schizophrenia. British Journal of Psychiatry, 157, 558-561.

-, Friston, K. J., Frith, C. D., et al (1992) Patterns of cerebral blood flow in schizophrenia. British Journal of Psychiatry, 160, 179-186.

Friston, K. J., Liddle, P. F., Frith, C. D., et al (1992) The left medial temporal region and schizophrenia: a PET study. Brain, $115,367-382$.

Hammersmith Hospital

Peter F. Liddle

Ducane Road

London W12 0HS

\section{Propofol and ECT}

SIR: We have been following with interest the recent correspondence in the Journal concerning the role of propofol in anaesthesia for ECT (Pippard, 1992; Haddad \& Benbow, 1992). Both Dr Pippard and Drs Haddad and Benbow warn against the use of propofol on the grounds that the well-demonstrated 